\title{
Effect of gallic acid on high fat diet-induced dyslipidaemia, hepatosteatosis and oxidative stress in rats
}

\author{
Chin-Lin Hsu and Gow-Chin Yen* \\ Department of Food Science and Biotechnology, National Chung Hsing University, 250 Kuokuang Road, Taichung 40227, Taiwan
}

(Received 20 November 2006 - Revised 17 March 2007 - Accepted 22 March 2007)

Gallic acid (GA) is a naturally abundant plant phenolic compound in the human diet and is known to reduce the risk of disease. In this study, the anti-obesity effect of GA in an animal model of diet-induced obesity was investigated. Obesity was induced in male Wistar rats by feeding them a high-fat diet (HFD). GA was given as a supplement at the levels of 50 and $100 \mathrm{mg} / \mathrm{kg}$ rat for a period of 10 weeks. The results showed that the body weight, organ weight of the liver and adipose tissue weights of peritoneal and epididymal tissues in the HFD + GA groups were significantly decreased as compared with the HFD group. Serum TAG, phospholipid, total cholesterol, LDL-cholesterol, insulin and leptin levels in the HFD + GA groups were significantly decreased as compared with the HFD group. Histological study showed that the lipid droplets of rats with HFD + GA diets were significantly smaller than those with HFD diets. Hepatic TAG and cholesterol levels in HFD + GA groups were significantly decreased as compared with the HFD group. Moreover, the consumption of GA reduced oxidative stress and GSSG content and enhanced the levels of glutathione, GSH peroxidase, GSH reductase and GSH $S$-transferase in the hepatic tissue of rats with HFD-induced obesity. These results demonstrate that intake of GA can be beneficial for the suppression of HFD-induced dyslipidaemia, hepatosteatosis and oxidative stress in rats.

Gallic acid: High-fat diet: Anti-obesity

Obesity is a serious health problem in industrialized countries and it has become prevalent in industrialized countries as a result of changes in lifestyle, especially in eating habits. Obesity is implicated in various diseases, including type II diabetes, hypertension, cancer and $\mathrm{CHD}^{1}$. Obesity is characterized at the cell biological level by an increase in the number and size of adipocytes differentiated from fibroblastic pre-adipocytes in adipose tissue ${ }^{2}$. Adipose tissue is vital for maintaining whole body energy homeostasis and consists of adipocytes, which store TAG as a fuel for the body. Excessive adipose tissue deposition is attributed to an imbalance between energy intake and energy expenditure ${ }^{3}$. The major health consequences of obesity are predictable given an understanding of the pathophysiology of increasing body fat. Therefore, prevention and treatment of obesity are relevant to health promotion.

Phenolic acids such as hydroxybenzoic acids and hydroxycinnamic acid are antioxidant compounds in fruits and vegetables $^{4}$. Gallic acid (3,4,5-trihydroxybenzoic acid; GA) is a naturally abundant phenolic compound in vegetables, such as asparagus, broccoli and aubergine ${ }^{5}$. It is reported to have antioxidant, antimutagenic and anticarcinogenic activity and is expected to reduce the risk of disease and brings health benefits through daily intake ${ }^{6}$. Epidemiological evidence has shown that dietary antioxidants play a role in the prevention of several chronic diseases such as cancer, CVD and diabetes $^{7,8}$. A number of studies have demonstrated that antioxidants may act as a regulator of obesity in mice or rats with high fat-diets (HFD) ${ }^{9,10}$. Research on phenolic acids is of current interest due to their important biological and pharmacological properties ${ }^{11}$. Our previous in vitro data indicated that GA has the highest inhibition of 3T3-L1 pre-adipocyte population growth $(63.9 \%)$ among the fifteen phenolic acids tested ${ }^{12}$. Nevertheless, the literature data regarding the in vivo effects of GA on anti-obesity effects are limited.

Obesity has been shown to be one of the conditions that decrease antioxidant capacity ${ }^{13,14}$. Obesity seems to decrease antioxidant defence by lowering the levels of antioxidant enzymes (catalase, glutathione peroxidase (GPx) and glutathione reductase $(\mathrm{GRd}))^{14}$. Cellular antioxidant defences against such oxidative stress involve antioxidant enzymes such as GPx, catalase and two forms of superoxide dismutase: a cytosolic $\mathrm{Cu} / \mathrm{Zn}$-dependent superoxide dismutase and a mitochondrial Mn-dependent superoxide dismutase ${ }^{15-17}$. Antioxidants have been reported to play an important role in enzymatic and non-enzymatic protection against oxidative stress-induced toxicity ${ }^{18,19}$. However, the effect of GA on HFD-induced oxidative stress in obese rats has not yet been investigated. We focused on the GA-enhanced antioxidant defence levels in the hepatic tissue of HFD-induced obese rats.

Abbreviations: GA, gallic acid; GPx, glutathione peroxidase; GRd, glutathione reductase; GST, glutathione $S$-transferase; HD, high dose; HFD, high-fat diet; LD, low dose; ND, normal diet.

* Corresponding author: Gow-Chin Yen, fax +886 4 22854378, email gcyen@nchu.edu.tw 
In the present paper we investigated the effect of GA on HFDinduced dyslipidaemia, hepatosteatosis and oxidative stress in rats. Thus, in the present study, growth parameters, weights of organ and adipose tissues, serum biochemical parameters, histology and the antioxidant defence system were measured in rats fed a normal diet (ND) and a HFD with or without GA.

\section{Methods}

\section{Animals, diets and experimental design}

Male Wistar rats (4 weeks old) were purchased from the National Science Council Animal Center, Taipei, Taiwan. Animals were housed individually in stainless steel cages in an air-conditioned room at $23 \pm 2{ }^{\circ} \mathrm{C}, 55-60 \%$ relative humidity and a $12 \mathrm{~h}$ light-dark cycle and they were given a laboratory rodent chow diet for 1 week. The rats were divided into normal and obese groups (six per group) and then fed with ND and HFD, respectively. The HFD group was divided into three groups according to whether they received supplemental GA for 10 weeks: the HFD group were fed HFD only; the HFD + GA (LD) group were fed HFD with a low dose (LD) of GA $(50 \mathrm{mg} / \mathrm{kg}$ rat $)$; the $\mathrm{HFD}+\mathrm{GA}$ (HD) group were fed HFD with a high dose (HD) of GA $(100 \mathrm{mg} / \mathrm{kg}$ rat). These rats were provided with semi-synthetic diets (Table 1) and water ad libitum throughout the experimental period. These animals should normally be able to consume $5 \%$ of their body weight in daily diets. The diets were stored in a $4^{\circ} \mathrm{C}$ cold chamber. Body weights, food intakes and food efficiency ratios were measured every day for 10 weeks. The food efficiency ratio, which is the ratio of body weight gain $(\mathrm{g} / \mathrm{d})$ to food intake $(\mathrm{g} / \mathrm{d})$, assesses utilization of food consumed. After overnight fasting, blood was withdrawn from the abdominal aorta under diethyl ether anaesthesia and serum was collected. The visceral tissues were excised immediately, rinsed, weighted and frozen in liquid N. All experimental procedures involving animals were conduced in accordance with the guidelines of the National Institutes of Health. The present experiment was approved by the Institutional Animal Care and Use Committee of National Chung Hsing University, Taichung, Taiwan.

Table 1. Composition of experimental high fat-diets (HFD)*

\begin{tabular}{lcccc}
\hline & & \multicolumn{3}{c}{ HFD } \\
\cline { 3 - 5 } $\begin{array}{l}\text { Ingredients } \\
\text { (g/kg dietary weight) }\end{array}$ & ND & Control & GA (LD) & GA (HD) \\
\hline Casein & 260 & 260 & 260 & 260 \\
Maize starch & 500 & 150 & 150 & 150 \\
Sucrose & 90 & 90 & 90 & 90 \\
Maize oil & 50 & - & - & - \\
Beef tallow & - & 400 & 400 & 400 \\
Cellulose & 50 & 50 & 49 & 48 \\
Mineral mixture & 40 & 40 & 40 & 40 \\
Vitamin mixture & 10 & 10 & 10 & 10 \\
GA & - & 0 & 1 & 2 \\
Metabolizable & $16 \cdot 11$ & 23.43 & 23.43 & 23.43 \\
$\quad$ energy (kJ/g) & & & & \\
\hline
\end{tabular}

${ }^{*}$ For details of diets and procedures, see Methods.

† Mineral and vitamin mixtures (AIN-76) were purchased from Oriental Yeast (Tokyo, Japan).

ND, normal diet; GA, gallic acid; LD, low dose; HD, high dose.

\section{Measurement of serum parameters}

Blood was placed into a sterile Vacutainer plastic tube (BD Vacutainer, Plymouth, UK). Serum was separated by centrifugation (4000 rpm, $10 \mathrm{~min}$ ) and transferred to Eppendorf tubes. All serum samples were stored at $-80^{\circ} \mathrm{C}$ until analysis. The concentrations of TAG, glucose, phospholipid, total cholesterol, LDL-cholesterol, HDL-cholesterol, aspartate aminotransferase, alanine aminotransferase, uric acid, creatinine, $\mathrm{Na}^{+}, \mathrm{K}^{+}$and $\mathrm{Cl}^{-}$in serum were measured with commercial kits (Bayer Corporation, Tarrytown, NY, USA). The concentrations of insulin and leptin in the serum were measured with rat insulin ELISA kits (Mercodia AB, Uppsala, Sweden) and leptin ELISA kits (BioVendor, Brno, Czech Republic).

\section{Haematoxylin/eosin and oil-red $O$ staining}

The studied animals were killed and liver samples were collected, fixed in $10 \%$ formalin buffered solution, cut into $5-\mu \mathrm{m}$ sections and stained with haematoxylin/eosin. Moreover, livers from the animals were frozen in liquid $\mathrm{N}$, embedded in an optimal temperature-cutting compound and cut into $5 \mu \mathrm{m}$ sections and stained with oil-red O. Haematoxylin/eosin and oil-red $\mathrm{O}$ staining was performed using standard techniques.

\section{Hepatic lipid analysis}

Liver lipids were extracted according to the methods of Folch et al. $^{20}$ and the concentrations of TAG and cholesterol were measured by the methods of Fletcher ${ }^{21}$ and Sperry \& Webb ${ }^{22}$.

\section{Determination of GSH and GSSG in the liver}

GSH and GSSG were determined after hepatic tissue was homogenized with PBS at a $\mathrm{pH}$ of 7.4. GSH and GSSG were determined using a glutathione assay kit (Cayman Chemical Company, Ann Arbor, MI, USA). The amounts of total GSH and GSSG were photometrically determined using a microplate reader (Awareness Technology, Palm City, FL, USA) at $405 \mathrm{~nm}$ and the amounts of GSH and GSSG were calculated.

\section{Assay of antioxidant enzymes in liver}

All antioxidant enzyme activities were determined after hepatic tissue was homogenized with PBS at a $\mathrm{pH}$ of 7.0. GPx activity was determined according to the method of Lawrence $\&$ Burk $^{23}$. Liver homogenate solution $(100 \mu \mathrm{l})$ was mixed with $800 \mu \mathrm{l} 100 \mathrm{mmol} / \mathrm{l}$ potassium phosphate buffer ( $\mathrm{pH} 7 \cdot 4)$, containing $1 \mathrm{mmol} / 1 \mathrm{EDTA}, 1 \mathrm{mmol} / 1 \mathrm{NaN}_{3}, 0.2 \mathrm{mmol} / 1 \mathrm{NADPH}$, $1 \mathrm{U} / \mathrm{ml} \mathrm{GRd}$ and $1 \mathrm{mmol} / \mathrm{l} \mathrm{GSH}$. After $5 \mathrm{~min}, 2.5 \mathrm{mmol} / 1 \mathrm{H}_{2} \mathrm{O}_{2}$ $(100 \mu \mathrm{l})$ was added to start the reaction. The absorbance change at $340 \mathrm{~nm}$ in $3 \mathrm{~min}$ was recorded. The enzyme activity was calculated using the value of $E_{340}=6220 / \mathrm{M}$ per $\mathrm{cm}$ and the result was expressed in units of $\mathrm{nmol} \mathrm{NADPH} / \mathrm{min}$ per mg protein.

GRd activity was determined according to the method of Bellomo et $\mathrm{al}^{24}$. Liver homogenate solution $(100 \mu \mathrm{l})$ was mixed with $900 \mu \mathrm{l} 100 \mathrm{mmol} / \mathrm{l}$ potassium phosphate 
buffer (pH 7.0), containing $1 \mathrm{mmol} / 1 \mathrm{MgCl}_{2} \cdot 6 \mathrm{H}_{2} \mathrm{O}, 50 \mathrm{mmol} /$ $1 \mathrm{GSSG}$ and $0.1 \mathrm{mmol} / \mathrm{l} \mathrm{NADPH}$, and was incubated at room temperature for $3 \mathrm{~min}$. The absorbance change at $340 \mathrm{~nm}$ in $3 \mathrm{~min}$ was recorded. The enzyme activity was calculated using the value of $E_{340}=6220 / \mathrm{M}$ per $\mathrm{cm}$ and the result was expressed in units of $\mathrm{nmol} \mathrm{NADPH} / \mathrm{min}$ per $\mathrm{mg}$ protein.

GSH $S$-transferase (GST) activity was determined according to the method of Habig et al. ${ }^{25}$. Liver homogenate solution $(100 \mu \mathrm{l})$ was well mixed with $880 \mu \mathrm{l} 100 \mathrm{mmol} / \mathrm{l}$ potassium phosphate buffer ( $\mathrm{pH} 6 \cdot 5$ ), containing $100 \mathrm{mmol} / \mathrm{l}$ GSH and $50 \mathrm{mmol} / 1$ 1-chloro-2,4-dinitrobenzene. The absorbance change at $340 \mathrm{~nm}$ in $3 \mathrm{~min}$ was recorded. The enzyme activity was calculated using the value of $E_{340}=9 \cdot 6 / \mathrm{mm}$ per $\mathrm{cm}$ and the result was expressed in units of nmol 1-chloro2,4-dinitrobenzene-GSH conjugated formed/min per mg protein.

\section{Statistical analysis}

All data are presented as means and standard deviations. ANOVA were performed using ANOVA procedures. Differences were considered to be significant at $95 \%$ CI.

\section{Results}

Effect of gallic acid on growth parameters

The composition of the diets is shown in Table 1. GA was added as $0.1 \%(50 \mathrm{mg} / \mathrm{kg}$ rat $)$ and $0.2 \%(100 \mathrm{mg} / \mathrm{kg}$ rat $)$ of the HFD. All rats were allowed free access to the test diets and water throughout the test period. The effect of GA on body weights, food intake and food efficiency in rats fed with a ND or HFD is shown in Fig. 1. After 10 weeks of feeding, body weights in the HFD group were heavier than those of the ND group. Moreover, the body weights of the HFD + GA groups were significantly decreased as compared with the HFD group $(P<0 \cdot 05)$. Food intake in the HFD group was as high as that in the ND or HFD + GA groups, but there were no significant differences among the four groups. The food efficiency in the HFD group was significantly higher than that in both the ND and HFD + GA groups $(P<0.05)$.

\section{Effect of gallic acid on organ and adipose tissue weights}

The organ and adipose tissue weights of the four groups are depicted in Table 2. There were no significant differences in the organ weights of the heart, spleen, lung and kidney

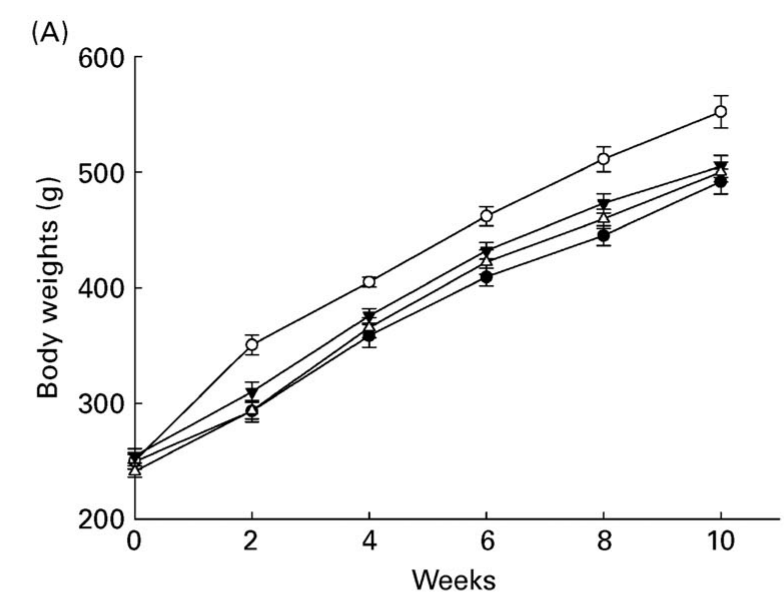

(B)

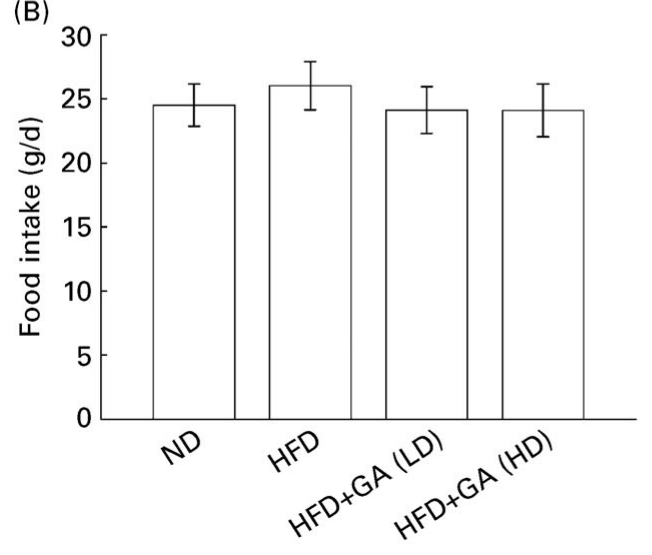

(C)

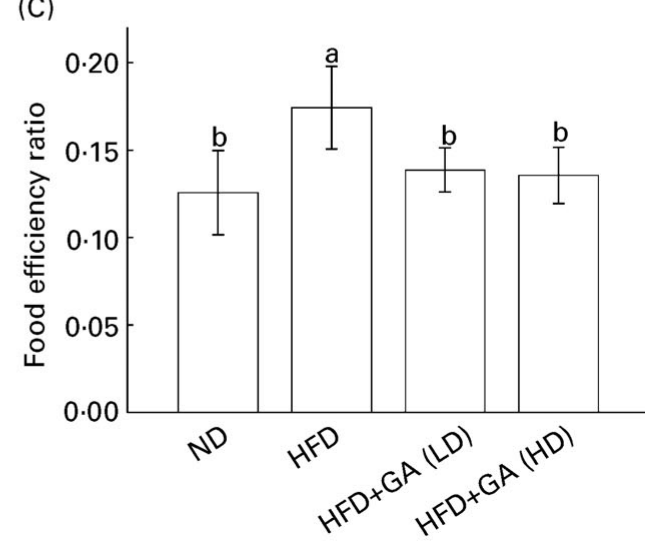

Fig. 1. Effect of gallic acid (GA) on (A) body weights $(-\bullet-$, normal diet (ND); $-\bigcirc-$, high-fat diet (HFD); $-\mathbf{\nabla}-$, HFD + GA (low dose; LD); $-\Delta-$, HFD + GA (high dose; HD); (B) food intake, (C) food efficiency ratio of rats with obesity induced by a HFD. Food efficiency ratio = body weight gain $(\mathrm{g} / \mathrm{d}) / \mathrm{food}$ intake $(\mathrm{g} / \mathrm{d})$. Values are means and standard deviations for six rats. ${ }^{a, b}$ Mean values with unlike letters were statistically significantly different $(P<0.05)$. For details of diets and procedures, see Methods. 
Table 2. Effect of gallic acid (GA) on the weights of organ and adipose tissue of rats with obesity induced by high fat-diet (HFD)* (Mean values and standard deviations for six rats per group)

\begin{tabular}{|c|c|c|c|c|c|c|c|c|}
\hline \multirow[b]{2}{*}{ Tissue weights ( $\mathrm{mg} / \mathrm{g}$ rat) } & \multicolumn{2}{|c|}{ ND } & \multicolumn{2}{|c|}{ HFD } & \multicolumn{2}{|c|}{$\mathrm{HFD}+\mathrm{GA}(\mathrm{LD})$} & \multicolumn{2}{|c|}{$\mathrm{HFD}+\mathrm{GA}(\mathrm{HD})$} \\
\hline & Mean & SD & Mean & SD & Mean & SD & Mean & SD \\
\hline Heart & 2.9 & 0.1 & $2 \cdot 7$ & 0.4 & 2.9 & 0.2 & $2 \cdot 8$ & 0.1 \\
\hline Liver & $25 \cdot 2^{b}$ & 1.4 & $30 \cdot 5^{a}$ & $3 \cdot 2$ & $26 \cdot 1^{\mathrm{b}}$ & $2 \cdot 0$ & $24 \cdot 8^{b}$ & 0.9 \\
\hline Spleen & 1.7 & 0.1 & 1.5 & 0.1 & 1.5 & 0.2 & 1.5 & 0.2 \\
\hline Lung & $3 \cdot 3$ & 0.2 & 2.9 & 0.4 & $3 \cdot 3$ & 0.3 & $3 \cdot 3$ & 0.2 \\
\hline Kidney & $5 \cdot 3$ & 0.3 & $5 \cdot 0$ & 0.5 & 4.9 & 0.5 & $5 \cdot 2$ & 0.4 \\
\hline Peritoneal fat & $21 \cdot 0^{c}$ & 4.7 & $39 \cdot 8^{a}$ & 4.9 & $32 \cdot 1^{\mathrm{b}}$ & 4.5 & $31 \cdot 2^{b}$ & $2 \cdot 3$ \\
\hline Epididymal fat & $18 \cdot 1^{\mathrm{C}}$ & 3.6 & $35 \cdot 5^{\mathrm{a}}$ & $5 \cdot 2$ & $28 \cdot 3^{\mathrm{b}}$ & $4 \cdot 1$ & $26 \cdot 2^{b}$ & 2.6 \\
\hline
\end{tabular}

${ }^{*}$ For details of diets and procedures, see Methods.

${ }^{a, b, c}$ Mean values within a row with unlike superscript letters were significantly different by ANOVA $(P<0.05)$.

ND, normal diet; LD, low dose; HD, high dose.

among the four groups. However, the weight of the liver in the HFD group was significantly increased as compared with the $\mathrm{ND}$ and HFD + GA groups $(P<0 \cdot 05)$. The adipose tissue weights of peritoneal fat and epididymal fat in the HFD + GA groups were significantly decreased as compared with those of the HFD group $(P<0 \cdot 05)$.

\section{Effect of gallic acid on serum biochemical parameters}

The serum biochemical parameters of the four groups are depicted in Table 3. Serum TAG levels in the HFD + GA groups were significantly decreased as compared with those in the HFD group $(P<0 \cdot 05)$. Serum glucose levels were not significantly different among the four groups. Serum phospholipid levels in the HFD group were significantly increased as compared with those in the other groups $(P<0 \cdot 05)$. Total cholesterol levels in the HFD group were higher than those in the other groups $(P<0.05)$, but there were no significant differences between the ND and HFD + GA groups. LDLcholesterol levels in the HFD + GA groups were significantly decreased as compared with those in the HFD group $(P<0.05)$, but there were no significant differences between the ND and HFD + GA (HD) groups. HDL-cholesterol levels were not significantly different among the four groups. There were no significant differences in serum aspartate aminotransferase, alanine aminotransferase, uric acid, creatinine, $\mathrm{Na}^{+}, \mathrm{K}^{+}$and $\mathrm{Cl}^{-}$levels among the four groups.

\section{Effect of gallic acid on serum leptin and insulin levels}

The effect of GA on serum insulin and leptin levels of obese rats induced by a HFD is shown in Fig. 2. Serum insulin levels in the HFD + GA groups were significantly decreased as compared with those in the HFD group $(P<0 \cdot 05)$ (Fig. 2(A)). These levels in the HFD + GA (HD) group were lower than those in the HFD + GA (LD) group. Serum leptin levels in the HFD + GA groups were significantly decreased as compared with those in the HFD group $(P<0.05)$ (Fig. 2(B)). The serum leptin levels were not significantly different between the ND and HFD + GA (HD) groups.

Table 3. Effect of gallic acid (GA) on the serum biochemical parameters of rats with obesity induced by high fat-diet (HFD)* (Mean values and standard deviations for six rats per group)

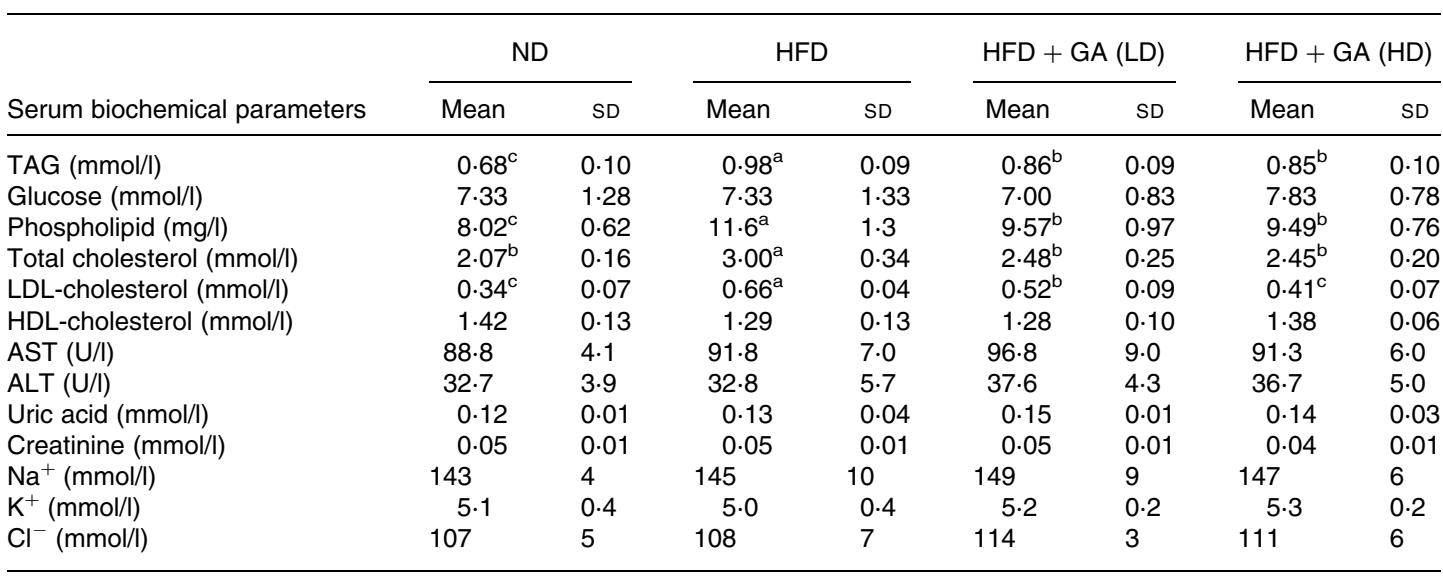

${ }^{*}$ For details of diets and procedures, see Methods.

a,b,c Mean values within a row with unlike superscript letters were significantly different by ANOVA $(P<0.05)$.

ND, normal diet; LD, low dose; HD, high dose; AST, aspartate aminotransferase; ALT, alanine aminotransferase. 
(A)

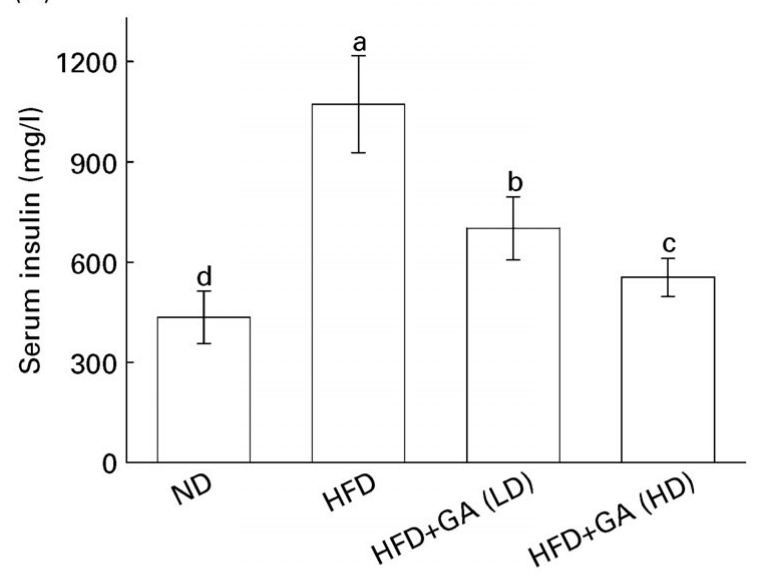

(B)

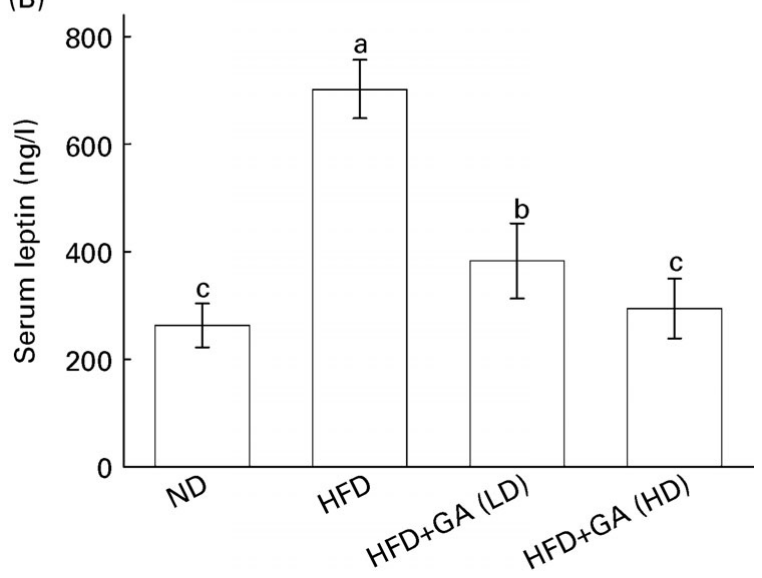

Fig. 2. Effect of gallic acid (GA) on (A) levels of serum insulin and (B) leptin of rats with obesity induced by a high-fat diet (HFD). ND, normal diet; LD, low dose; HD, high dose. Values are means and standard deviations for six rats. ${ }^{a, b, c, d}$ Mean values with unlike letters were statistically significantly different $(P<0.05)$. For details of diets and procedures, see Methods.

\section{Effect of gallic acid on hepatosteatosis}

As demonstrated in Fig. 3(A), haematoxylin and eosin staining showed normal liver architecture in the ND group. The HFD group showed more profound steatosis with macrovesicular fat accumulation. The HFD + GA groups showed microvesicular fat accumulation. However, this phenomenon in the HFD + GA (HD) group was less significant than in the HFD + GA (LD) group. These changes were confirmed with oil-red $O$ staining. Staining with oil-red O confirmed the presence of lipid droplets within hepatocytes of the rats fed HFD (Fig. 3(B)). The number of lipid droplets of the HFD + GA groups was smaller than that of the HFD group.

Hepatic TAG levels in the HFD + GA groups were significantly decreased as compared with the HFD group $(P<0.05)$ (Fig. 4(A)). Hepatic TAG levels in the HFD + GA (HD) group were lower than those in the HFD + GA (LD) group $(P<0 \cdot 05)$. Liver cholesterol levels were higher in the HFD group $(P<0.05)$, but there was no significant difference between the ND and HFD + GA groups (Fig. 4(B)).

\section{Effect of gallic acid on GSH and GSSG contents}

GSH constitutes the first line of defence against free radicals. As shown in Table 4, the HFD group showed a significant reduction in GSH content $(P<0.05)$ in the livers of rats with obesity induced by a HFD. The GSH content in the HFD + GA groups was significantly increased as compared with that of the HFD group $(P<0.05)$. The GSSG content in the HFD + GA groups was significantly decreased as compared with that of the HFD group $(P<0 \cdot 05)$.

\section{Effect of gallic acid on antioxidant enzymes}

As shown in Table 5, the HFD group showed a significant reduction in the activities of antioxidant enzymes $(P<0.05)$ in the livers of rats with obesity induced by a HFD. The GSH-dependent antioxidant enzymes activities GPx, GRd and GST showed 20,27 and $44 \%$ reductions, respectively, in the HFD group when compared with the ND group. Antioxidant enzymes (GPx, GRd and GST) in the HFD + GA groups were significantly increased as compared with those in the HFD group $(P<0 \cdot 05)$.

\section{Discussion}

Dietary fat is one of the most important environmental factors associated with the incidence of CVD; high cholesterol and saturated fat diets have been shown to promote atherosclero$\mathrm{sis}^{26}$. Han et $\mathrm{al}^{27}$ indicated that increases in body weight, fat storage, hepatic TAG content and the frequency of fatty liver are all noted. The present study was designed to establish if short periods of alternations between the various diets (ND, HFD and HFD + GA) in rats would result in different levels of dyslipidaemia, hepatosteatosis and oxidative stress. The present in vitro data indicated that the inhibition of phenolic acids on the growth of 3T3-L1 pre-adipocytes is well correlated to the antioxidant activity of the phenolic acids ${ }^{12}$. In the present study, we focused on the effect of GA on rats with obesity induced by a high-energy diet. Many studies indicated that obesity is induced in mice and rats by feeding a high-energy diet containing $40 \%$ beef tallow ${ }^{9,28,29}$. In the present study, GA was given as a supplement at the levels of 50 and $100 \mathrm{mg} / \mathrm{kg}$ rat for a period of 10 weeks. The range of doses used in the present study was consistent with those in other studies on the effect of GA on rats ${ }^{30,31}$. We found that feeding GA for 10 weeks suppressed the increases in body weight, organ weight of the liver and adipose tissue weights of peritoneal fat and epididymal fat induced by a HFD (Fig. 1 and Table 2). However, the plant-derived phenolic compound genistein is known to exhibit several biological properties. The reports indicated that genistein can reduce fat deposition in the adipose tissue of mice ${ }^{32,33}$.

Lavie \& Milani ${ }^{34}$ indicated that obesity adversely affects plasma lipids, especially by increasing TAG and decreasing the level of HDL-cholesterol. We also found that the HFD + GA groups had significantly decreased levels of TAG, phospholipids, total cholesterol and LDL-cholesterol (Table 3). The HFD might lead to an increase in the synthesis of phospholipids and cholesterol esters in rats ${ }^{35}$. Hyson et al $^{36}$ indicated that the blood level of LDL-cholesterol and its oxidation are related to cardiovascular risk and the 

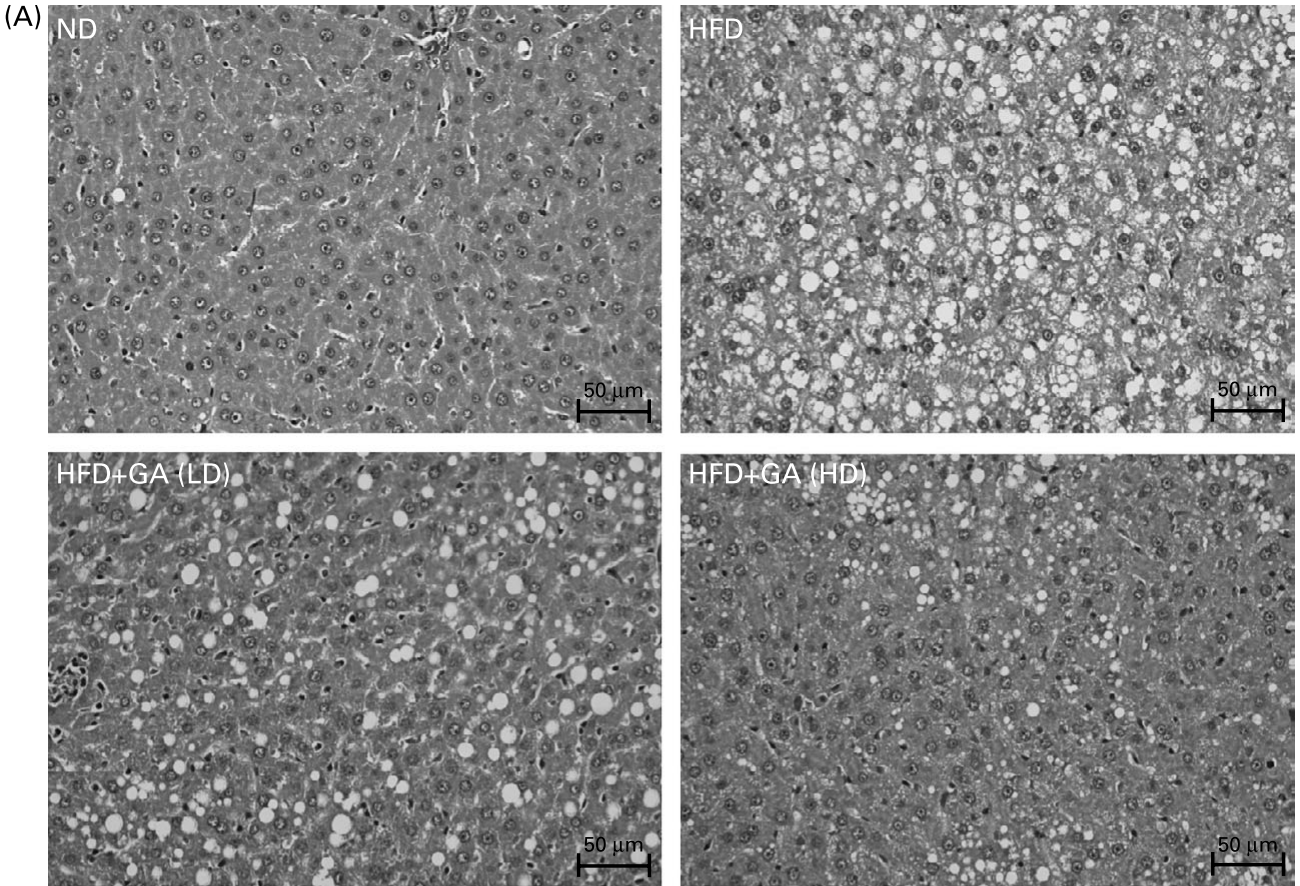

(B)
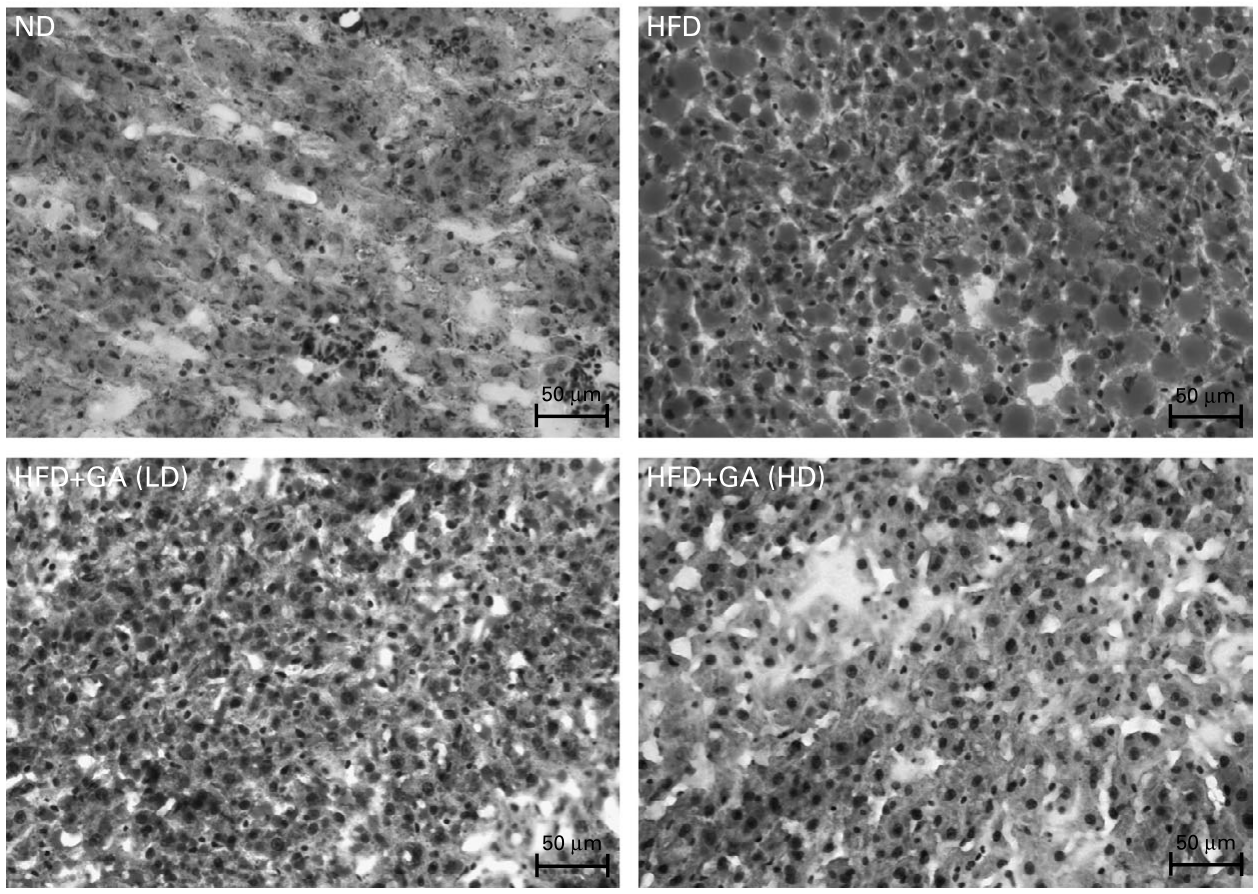

Fig. 3. Effect of gallic acid on hepatosteatosis of rats with obesity induced by a high fat-diet. Livers were stained with (A) haematoxylin and eosin or (B) oil-red O Original magnification $\times 200$. For details of diets and procedures, see Methods.

LDL-cholesterol level of blood is an index of health. Serum insulin and leptin levels in the HFD + GA groups were significantly decreased as compared with those in the HFD group (Fig. 2). Fried et al. ${ }^{37}$ indicated that basal levels of leptin are known to be strongly positively correlated with body fat on a HFD. The report indicated that leptin might contribute to hepatic steatosis by promoting insulin resistance and also by altering insulin signalling in hepatocytes, so as to promote increased intracellular fatty acids ${ }^{38}$. Therefore, GA prevents the increase of these levels due to its decrease of the body fat content of rats fed with HFD. However, serum glucose levels were not significantly different among the four groups. The present data indicated that intake of GA (50 and $100 \mathrm{mg} / \mathrm{kg}$ rat) for 10 weeks in Wistar rats did not affect the serum biochemical data (aspartate aminotransferase, alanine aminotransferase, uric acid, creatinine, $\mathrm{Na}^{+}, \mathrm{K}^{+}$and $\left.\mathrm{Cl}^{-}\right)$. Niho et $a l^{30}$ reported that intake of GA $(119 \mathrm{mg} / \mathrm{kg}$ per d) for 13 weeks is determined to be a no-observedadverse-effect level in male rats. The dosage used in the present study was consistent with those in many other studies on 
(A)

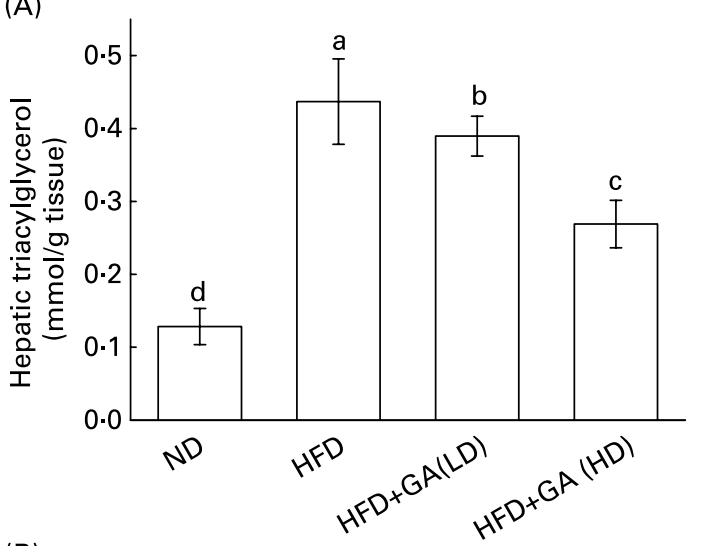

(B)

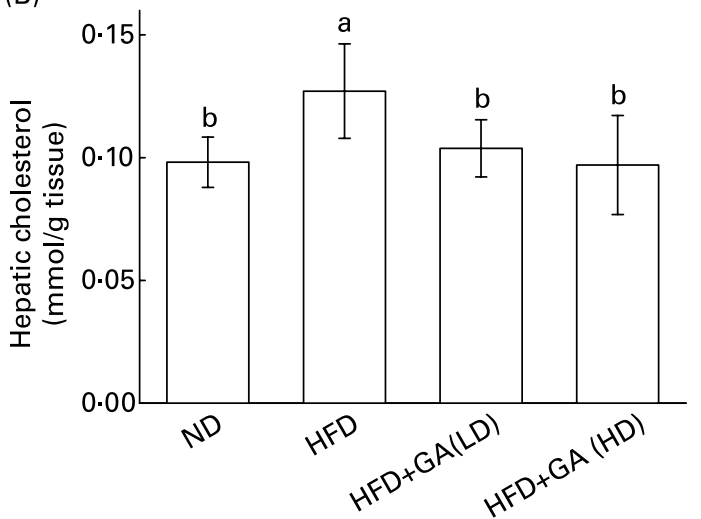

Fig. 4. Effect of gallic acid on (A) hepatic TAG and (B) cholesterol of rats with obesity induced by a high fat-diet. Values are means with their standard deviations for six rats. ${ }^{a, b, c, d}$ Mean values with unlike letters were statistically significantly different $(P<0.05)$. For details of diets and procedures, see Methods.

the inhibitory effect of intake of phenolic acids in rats ${ }^{39,40}$. The data of the serum biochemical parameters (aspartate aminotransferase, alanine aminotransferase, uric acid, creatinine, $\mathrm{Na}^{+}, \mathrm{K}^{+}$and $\mathrm{Cl}^{-}$) might also support the dosage used to be a no-observed-adverse-effect level in male rats. Thus, we assume that GA has an anti-obesity effect via suppression of dyslipidaemia, hepatosteatosis and oxidative stress in obese rats.

Table 4. Effect of gallic acid (GA) on the contents of GSH and GSSG in liver of rats with obesity induced by high fat-diet (HFD)*

(Mean values and standard deviations for six rats per group)

\begin{tabular}{llllll}
\hline & \multicolumn{3}{c}{$\mu$ mol/mg protein } \\
\cline { 2 - 3 } \cline { 5 - 6 } & \multicolumn{2}{c}{ GSH } & & \multicolumn{2}{c}{ GSSG } \\
\cline { 2 - 3 } \cline { 5 - 6 } Content & Mean & SD & & Mean & SD \\
\hline ND & $3.50^{\mathrm{a}}$ & 0.21 & & $0.26^{\mathrm{c}}$ & 0.03 \\
HFD & $1.09^{\mathrm{d}}$ & 0.18 & & $0.39^{\mathrm{a}}$ & 0.06 \\
HFD + GA (LD) & $1.42^{\mathrm{c}}$ & 0.25 & & $0.33^{\mathrm{b}}$ & 0.03 \\
HFD + GA (HD) & $2.26^{\mathrm{b}}$ & 0.24 & & $0.28^{\mathrm{bc}}$ & 0.06 \\
\hline
\end{tabular}

${ }^{*}$ For details of diets and procedures, see Methods.

$\mathrm{a}, \mathrm{b}, \mathrm{c}, \mathrm{d}$ Mean values within a column with unlike superscript letters were significantly different by ANOVA $(P<0.05)$.

ND, normal diet; LD, low dose; HD, high dose.
Table 5. Effect of gallic acid (GA) on antioxidant enzymes in liver of rats with obesity induced by high fat-diet (HFD)*

(Mean values and standard deviations for six rats per group)

\begin{tabular}{|c|c|c|c|c|c|c|}
\hline \multirow[b]{3}{*}{ Activities } & \multicolumn{6}{|c|}{$\mathrm{nmol} / \mathrm{min}$ per $\mathrm{mg}$ protein } \\
\hline & \multicolumn{2}{|c|}{ GPx } & \multicolumn{2}{|c|}{ GRd } & \multicolumn{2}{|c|}{ GST } \\
\hline & Mean & SD & Mean & SD & Mean & SL \\
\hline ND & $196^{\mathrm{a}}$ & $6 \cdot 3$ & $39.7^{\mathrm{a}}$ & $3 \cdot 8$ & $526^{a}$ & \\
\hline HFD & $156^{\mathrm{c}}$ & 11 & $29.0^{\mathrm{b}}$ & 3.8 & $297^{\mathrm{C}}$ & \\
\hline $\mathrm{HFD}+\mathrm{GA}(\mathrm{LD})$ & $181^{\mathrm{b}}$ & 13 & $32 \cdot 3^{b}$ & 5.9 & $405^{b}$ & 2 \\
\hline $\mathrm{HFD}+\mathrm{GA}(\mathrm{HD})$ & $182^{b}$ & 12 & $38.5^{\mathrm{a}}$ & 4.7 & $434^{\mathrm{b}}$ & 4 \\
\hline
\end{tabular}

${ }^{*}$ For details of diets and procedures, see Methods.

${ }^{a, b, c}$ Mean values within a column with unlike superscript letters were significantly different by ANOVA $(P<0.05)$.

GPx, glutathione peroxidase; GRd, glutathione reductase; GST, glutathione $S$-transferase; LD, low dose; HD, high dose.

The liver is the central organ for cholesterol, phospholipid, TAG and lipoprotein metabolism. In the histology study (haematoxylin-eosin staining and oil-red $\mathrm{O}$ staining), the number of lipid droplets of the HFD + GA groups was significantly reduced as compared with that of the HFD group (Fig. 3). In obesity, the liver is the receiver of large amounts of fatty acids, which cause its steatosis ${ }^{41}$. The present data indicated that intake of GA for 10 weeks suppressed the increases in the levels of hepatic TAG and cholesterol induced by a HFD (Fig. 4). Moreover, reactive oxygen species have been found to be one of the main factors causing liver steato$\operatorname{sis}^{42,43}$. Reports have indicated that adiponectin reduces atherosclerosis by activating the insulin effect ${ }^{44,45}$ and adiponectin increases fatty acid $\beta$-oxidation and energy expenditure through an improvement in insulin resistance ${ }^{46}$.

In animal and human studies, obesity is associated with a decrease in tissue or plasma antioxidant capacity ${ }^{47,48}$. Phenolic compounds have been considered to play an important antioxidant role as dietary antioxidants for the prevention of oxidative damage in living systems ${ }^{49}$. GSH constitutes the first line of defence against free radicals in the liver and is also responsible for the maintenance of protein thiols and acts as a substrate for GPx and GST ${ }^{50}$. The present data indicate that GSH content was depleted in the rats with obesity induced by a HFD and were restored after the treatment of GA (Table 4). Enzymatic antioxidants, such as superoxide dismutase, catalase or GPx, can scavenge reactive oxygen species and free radicals or prevent their formation ${ }^{51}$. The present results showed that antioxidant enzyme activities (GPx, GRd and GST) in the HFD group were significantly decreased, and the HFD + GA groups had significantly increased activities of antioxidant enzymes in the liver (Table 5). The reports indicate that antioxidants can modify cholesterol absorption and increase antioxidant status $^{52,53}$. Several studies, such as that by Liou et al. ${ }^{54}$, have shown that hyperlipidaemia reduces the strength of the antioxidative defence system. Mehta et $_{\text {al }}{ }^{55}$ indicated that HFD lead to liver injury and insulin resistance through oxidative stress. Thus, we hypothesize that the possible explanation for reducing obesity following the consumption of GA is a reduction in oxidative stress in rats fed with HFD.

In conclusion, the present results demonstrate for the first time that the addition of GA to the diet decreases body weight gain, the weights of liver and adipose tissue, serum 
parameters (TAG, phospholipid, total cholesterol, LDLcholesterol, insulin and leptin) and hepatic steatosis. GA reduced oxidative stress (reduced GSSG and enhanced GSH, GPx, GRd and GST) in rats with obesity induced by a HFD. These results provide initial evidence that GA may be useful for the treatment of obesity and raise the possibility of a new application as a health supplement.

\section{Acknowledgements}

This research was partially supported by the Department of Health (DOH95-TD-F-113-002), Taiwan, Republic of China.

\section{References}

1. Kopelman PG (2000) Obesity as a medical problem. Nature 404, 635-643.

2. Furuyashiki T, Nagayasu H, Aoki Y, Bessho H, Hashimoto T, Kanazawa K \& Ashida H (2004) Tea catechin suppresses adipocyte differentiation accompanied by down-regulation of PPARgamma2 and C/EBPalpha in 3T3-L1 cells. Biosci Biotechnol Biochem 68, 2353-2359.

3. Prins JB \& O'Rahilly S (1997) Regulation of adipose cell number in man. Clin Sci 92, 3-11.

4. Bagchi D, Hassoum EA, Bagchi M \& Stohs SJ (1993) Protective effects of antioxidants against Endrin-induced hepatic lipid/peroxidantion, DNA damage and excretion of urinary lipid metabolites. Free Radic Biol Med 15, 217-222.

5. Yeh CT \& Yen GC (2005) Effect of vegetables on human phenolsulfotransferases in relation to their antioxidant activity and total phenolics. Free Radic Res 39, 893-904.

6. Galati G \& O'Brien PJ (2004) Potential toxicity of flavonoids and other dietary phenolics: significance for their chemopreventive and anticancer properties. Free Radic Biol Med 37, 287-303.

7. Cadenas E \& Packer L (2002) Handbook of Antioxidants, 2nd edn., pp. 712. New York: Marcel Dekker Inc.

8. Willcox JK, Ash SL \& Catignani GL (2004) Antioxidant and prevention of chronic disease. Crit Rev Food Sci Nutr 44, 275-295.

9. Han LH, Sumiyoshi M, Zhang J, Liu MX, Zhang XF, Zheng YN, Okuda H \& Kimura Y (2003) Anti-obesity action of Salix matsudana leaves (Part 1). Anti-obesity action by polyphenols of Salix matsudana in high fat-diet treated rodent animals. Phytother Res 17, 1188-1194.

10. Kuda T, Iwai A \& Yano T (2004) Effect of red pepper Capsicum annuum var. conoides and garlic Allium sativum on plasma lipid levels and cecal microflora in mice fed beef tallow. Food Chem Toxicol 42, 1695-1700.

11. Tanaka T, Kojima T, Kawamori T, Yoshimi N \& Mori H (1993) Chemoprevention of diethynitrosamine-induced hepatocarcinogenesis by a simple phenolic acid protocatechuic acid in rats. Cancer Res 53, 2775-2779.

12. Hsu CL, Huang SL \& Yen GC (2006) Inhibitory effect of phenolic acids on proliferation of 3T3-L1 preadipocytes in relation to their antioxidant activity. $J$ Agric Food Chem 54, 4191-4197.

13. Asayama K, Nakane T, Dobashi K, Kodera K, Hayashibe H, Uchida N \& Nakazawa S (2001) Effect of obesity and troglitazone on expression of two glutathione peroxidases: cellular and extracellular types in serum, kidney and adipose tissue. Free Radic Res 34, 337-347.

14. Carmiel-Haggai M, Cederbaum AI \& Nieto N (2005) A high-fat diet leads to the progression of non-alcoholic fatty liver disease in obese rats. FASEB $J \mathbf{1 9}, 136-138$.
15. Tribble DL, Aw TY \& Jones DP (1987) The pathophysiological significance of lipid peroxidation in oxidative cell injury. Hepatology 7, 377-386.

16. Fridovich I (1989) Superoxide dismutases. An adaptation to a paramagnetic gas. J Bio Chem 264, 7761-7764.

17. Sies H (1993) Strategies of antioxidant defense. Eur J Biochem 215, 213-219.

18. Anjaneyulu M, Tirkey N \& Chopra K (2003) Attenuation of cyclosporine-induced renal dysfunction by catechin: possible antioxidant mechanism. Ren Fail 25, 691-707.

19. Singh D, Chander V \& Chopra K (2005) Protective effect of catechin on ischemia-reperfusion-induced renal injury in rats. Pharmacol Rep 57, 70-76.

20. Folch J, Lees M \& Sloane-Stanley GH (1957) A simple method for the isolation and purification of total lipids from animal tissues. J Biol Chem 226, 497-509.

21. Fletcher MJ (1968) A colorimetric method for estimating serum triglycerides. Clin Chim Acta 22, 393-397.

22. Sperry WM \& Webb M (1950) A revision of the ShoenheimerSperry method for cholesterol determination. J Biol Chem 187, 97-106.

23. Lawrence RA \& Burk RF (1976) Glutathione peroxidase activity in selenium-deficient rat liver. Biochem Biophys Res Commun 71, 952-958.

24. Bellomo G, Mirabelli F, Dimonte D, Richelmi P, Thor H, Orrenius C \& Orrenius S (1987) Formation and reduction of glutathione-mixed disulfides during oxidative stress. Biochem Pharmacol 36, 1313-1320.

25. Habig WH, Pabst MJ \& Jakoby WB (1974) Glutathione S-transferase. The first enzymatic step in mercapturic acid formation. J Biol Chem 249, 7130-7139.

26. McNamara DJ (2000) Dietary cholesterol and atherosclerosis. Biochim Biophys Acta 1529, 310-320.

27. Han LK, Takaku T, Li J, Kimura Y \& Okuda H (1999) Antiobesity action of oolong tea. Int J Obes Relat Metab Disord 23, 98-105.

28. Han LK, Xu BJ, Kimura Y, Zheng YN \& Okuda H (2000) Platycodi radix affects lipid metabolism in mice with high fat diet-induced obesity. J Nutr 130, 2760-2764.

29. Han LK, Kimura Y, Kawashima M, Takaku T, Taniyama T, Hayashi T, Zheng YN \& Okuda H (2001) Anti-obesity effects in rodents of dietary teasaponin, a lipase inhibitor. Int $J$ Obes Relat Metab Disord 25, 1459-1464.

30. Niho N, Shibutani M, Tamura T, Toyoda K, Uneyama C, Takahashi N \& Hirose M (2001) Subchronic toxicity study of gallic acid by oral administration in F344 rats. Food Chem Toxicol 39, 1063-1070.

31. Yeh CT \& Yen GC (2006) Induction of hepatic antioxidant enzymes by phenolic acids in rats is accompanied by increased levels of multidrug resistance-associated protein $3 \mathrm{mRNA}$ expression. $J$ Nutr 136, 11-15.

32. Naaz A, Yellayi S, Zakroczymski MA, Bunick D, Doerge DR, Lubahn DB, Helferich WG \& Cooke PS (2003) The soy isoflavone genistein decreases adipose deposition in mice. Endocrinology 144, 3315-3320.

33. Kim S, Sohn I, Lee YS \& Lee YS (2005) Hepatic gene expression profiles are altered by genistein supplementation in mice with diet-induced obesity. J Nutr 135, 33-41.

34. Lavie CJ \& Milani RV (2003) Obesity and cardiovascular disease: the Hippocrates paradox? J Am Coll Cardiol 42, 677-679.

35. Jayakumar SM, Nalini N \& Venugopal PM (1991) Effect of ginger (Zingifer officinale) on lipids in rats fed atherogenic diet. J Clin Biochem Nutr 27, 79-82.

36. Hyson DA, Schneeman BO \& Davis PA (2002) Almonds and almond oil have similar effects on plasma lipids and LDL oxidation in healthy men and women. $J$ Nutr 132, $703-707$ 
37. Fried SK, Ricci MR, Russell CD \& Laferrere B (2000) Regulation of leptin production in humans. $J$ Nutr 130, 3127S-3131S.

38. Uygun A, Kadayifci A, Yesilova Z, et al. (2000) Serum leptin levels in patients with nonalcoholic steatohepatitis. Am J Gastroenterol 95, 3584-3589.

39. Choi I, Park Y, Choi H \& Lee EH (2006) Anti-adipogenic activity of rutin in 3T3-L1 cells and mice fed with high-fat diet. Biofactors 26, 273-281.

40. Jadon A, Bhadauria M \& Shukla S (2007) Protective effect of Terminalia belerica Roxb. and gallic acid against carbon tetrachloride induced damage in albino rats. J Ethnopharmacol 109, 214-218.

41. Festi D, Colecchia A, Sacco T, Bondi M, Roda E \& Marchesini G (2004) Hepatic steatosis in obese patients: clinical aspects and prognostic significance. Obes Rev 5, 27-42.

42. Laurent A, Nicco C, Tran Van Nhieu J, et al. (2004) Pivotal role of superoxide anion and beneficial effect of antioxidant molecules in murine steatohepatitis. Hepatology 39, 1277-1285.

43. Pessayre D, Fromenty B \& Mansouri A (2004) Mitochondrial injury in steatohepatitis. Eur $J$ Gastroenterol Hepatol 16, $1095-1105$

44. Pajvani UB \& Scherer PE (2003) Adiponectin: systemic contributor to insulin sensitivity. Curr Diab Rep 3, 207-213.

45. Tschritter O, Fritsche A, Thamer C, Haap M, Shirkavand F, Rahe S, Staiger H, Maerker E, Haring H \& Stumvoll M (2003) Plasma adiponectin concentrations predict insulin sensitivity of both glucose and lipid metabolism. Diabetes 52, 239-243.

46. Nagasawa A, Fukui K, Funahashi T, Maeda N, Shimomura I, Kihara S, Waki M, Takamatsu K \& Matsuzawa Y (2002) Effects of soy protein diet on the expression of adipose genes and plasma adiponectin. Horm Metab Res 34, 635-639.
47. Olusi SO (2002) Obesity is an independent risk factor for plasma lipid peroxidation and depletion of erythrocyte cytoprotectic enzymes in humans. Int J Obes Relat Metab Disord 26, $1159-1164$

48. Ozata M, Mergen M, Oktenli C, Aydin A, Sanisoglu SY, Bolu E, Yilmaz MI, Sayal A, Isimer A \& Ozdemir IC (2002) Increased oxidative stress and hypozincemia in male obesity. Clin Biochem 35, 627-631.

49. Hertog MG, Feskens EJ, Hollman PC, Katan MB \& Kromhout D (1993) Dietary antioxidant flavonoids and risk of coronary heart disease: the Zutphen Elderly Study. Lancet 342, 1007-1011.

50. Prakash J, Gupta SK, Kochupillai V, Singh N, Gupta YK \& Joshi S (2001) Chemopreventive activity of Withania somnifera in experimentally induced fibrosarcoma tumours in Swiss albion mice. Phytother Res 15, 240-244.

51. Husain K, Mejia J, Lalla J \& Kazin S (2005) Dose response of alcohol-induced changes in BP, nitric oxide and antioxidants in rat plasma. Pharmacol Res 51, 337-343.

52. Nicolle C, Cardinault N, Aprikian O, et al. (2003) Effect of carrot intake on cholesterol metabolism and on antioxidant status in cholesterol-fed rat. Eur J Nutr 42, 254-261.

53. Ko JH, Lee SJ \& Lim KT (2005) 36-kDa glycoprotein isolated from Rhus verniciflua Stokes fruit has a protective activity to glucose/glucose oxidase-induced apoptosis in NIH/3T3 cells. Toxicol in Vitro 19, 353-363.

54. Liou W, Chang LY, Geuze HJ, Strous GJ, Crapo JD \& Slot JW (1993) Distribution of CuZn superoxide dismutase in rat liver. Free Radic Biol Med 14, 201-207.

55. Mehta K, Van Thiel DH, Shah N \& Mobarhan S (2002) Nonalcoholic fatty liver disease: pathogenesis and the role of antioxidants. Nutr Rev 60, 289-293. 